\title{
Factors Influencing Physical Activity in Adolescents with Complex Congenital Heart Disease
}

\author{
Su Jin Kwon ${ }^{1}$, Eun Kyoung Choi ${ }^{2}$, Kyung Hee Lee ${ }^{2}$, Yu-Mi Im $^{3}$ \\ ${ }^{1}$ Advanced Practice Nurse, Congenital Heart Disease Center, Asan Medical Center, Seoul; ${ }^{2}$ Assistant Professor, College of Nursing • Mo-Im Kim Nursing Research \\ Institute, Yonsei University, Seoul; ${ }^{3}$ Assistant Professor, Seoul Women's College of Nursing, Seoul, Korea
}

Purpose: We aimed to identify factors influencing physical activity in adolescents with complex congenital heart disease. Methods: We recruited 92 adolescents with complex congenital heart disease from a tertiary medical center in Seoul, measured their levels of physical activity, and identified factors that influenced their physical activity levels using the Global Physical Activity Questionnaire, the New York Heart Association classification, congenital heart disease complexity, the Self-Efficacy Scale, and the Parental Bonding Instrument scale. Stepwise multiple linear regression was used to determine factors influencing physical activity. Results: Total physical activity was higher in males than in females $(\mathrm{t}=4.46, p<.001)$. Adolescents who participated in school physical education classes engaged in more physical activity than those who did not $(\mathrm{t}=6.77, p<.001)$. Higher self-efficacy $(\beta=.41, p<.001)$, male gender $(\beta=.37, p<.001)$ and participation in school physical education classes $(\beta=.19, p=.042)$ were associated with a higher likelihood of engagement in physical activity. Conclusion: It is necessary to develop nursing interventions that enhance self-efficacy in order to promote physical activity in adolescents with complex congenital heart disease. Physical activity should also be promoted in an individualized manner, taking into account gender, disease severity, and parental attitude.

Key words: Congenital heart defects; Physical activity; Parenting; Self-efficacy; Adolescents

\section{Corresponding author Eun Kyoung Choi \\ https://orcid.org/0000-0003-4622-2437}

College of Nursing, Yonsei University,

50-1 Yonsei-ro, Sedaemun-gu, Seoul 03722, Korea

TEL +82-2-2228-3340 FAX +82-2-392-5440

E-MAIL ekchoi@yuhs.ac

*This article was adapted from a thesis by Su Jin Kwon in partial fulfillment of the requirements for the master's degree at Yonsei University of Korea.

*This study was supported by Chijung Sim scholarship of the College of Nursing of Yonsei University in 2018.

Received Feb 12, 2019 Revised Mar 20, 2019 Accepted Mar 23, 2019

(a) This is an Open Access article distributed under the terms of the Creative Commons Attribution NonCommercial License (http://creativecommons.org/licenses/by-nc/4.0/) which permits unrestricted noncommercial use, distribution, and reproduction in any medium, provided the original work is properly cited.

\section{INTRODUCTION}

\section{Need for Study}

Although Korea's birthrate is rapidly falling, the percentage of infants born with congenital anomalies is gradually increasing. The number of congenital heart disease operation performed annually has increased from 4546 in 2006 to 5398 in 2016, an increase of 1000 within a decade [1,2]. According to a 2017 report by the American Heart Association (AHA), mortality rates from complex congenital heart diseases have decreased by $22 \%$ since 1979 . Advanced techniques to detect cardiac lesions, improved diagnosis and management strategies, and surgical interventions have contributed to higher survival rates of infants with congenital heart disease through adulthood [3,4]. Although infant survival rates have increased, the incidence of long-term arrhythmia and cardiac insufficiency has increased among survivors previously diagnosed with congenital heart disease. Therefore, regular monitoring of patients with congenital heart disease from infancy, through adolescence and extending into adulthood is necessary [5].

During growth, illnesses in adolescents might not be measurable in the same way as in adults although poor health in adolescence can affect health in adulthood. Therefore, appro- 
priate interventions for health management are necessary starting in adolescence, and positive health behaviors must be promoted to ensure a healthy adult life [6]. Congenital heart disease management in Korea currently focuses on promoting physical health, as there is a lack of awareness regarding multimodal approaches to health management, such as physical activity, career counseling, pregnancy choices, social activities, and quality of life [7].

Physical activity impacts adolescent health positively; however, almost half of patients with congenital heart disease rarely follow physical activity recommendations [8]. The AHA emphasized the importance of a physically active life and positive habits related to health and welfare in children and adults with congenital heart disease, noting that physical activity should be limited only when there is arrhythmia [9]. In addition, it has been reported that regular physical activity improves motor ability, the musculoskeletal system, blood vessels, and immune functions, and also benefits a person's mental and social welfare well-being, quality of life, and self-efficacy; additionally, the risk of acquired heart diseases can be reduced by regular physical activity $[9,10]$.

Although it is theoretically evident that regular physical activities have improved one's quality of life, a lot of adolescents with congenital heart disease have been found lack of physical activity $[8,11]$. Previous studies have reported several factors that promote or limit physical activity among adolescents with congenital heart disease, and self-efficacy was found to positively promote physical activity in adolescents with congenital heart disease [12]. Sable et al. [13] pointed out that the type of cardiac disorder and disease severity are important factors influencing decisions regarding the type of physical activity. However, some additional factors are more important, such as parental attitudes, recommendations from medical staff, the effect of exercise, and other adolescent interests [13]. Adolescents habits also affect physical activity [9]. Habits that encourage a low level of physical activity may be due to overprotection by parents or others, and such factors were found to be common among patients with complex congenital heart disease [11,14]. Additionally, it was observed that adolescents with complex congenital heart disease generally failed to practice a proper amount of physical activity as recommended by the World Health Organization (WHO), and that their quality of life was also relatively low [11].

Lack of physical activity is a risk factor for noninfectious diseases such as cardiovascular disease, ischemic stroke, type II diabetes mellitus, obesity, colon cancer, and breast cancer. The WHO developed the Global Physical Activity Questionnaire (GPAQ) to investigate analyze factors causing such noninfectious diseases and to compare the amount of physical activity across countries [15]. Several studies have used the GPAQ to investigate physical activity levels, but most have focused on adults. There have been few studies, at home and abroad, that examined factors influencing physical activity in adolescents with congenital heart disease, particularly complex congenital heart disease. Hence, it is necessary to analyze the extent to which the factors suggested in previous studies affect physical activity in this population.

The present study aimed to examine the characteristics of adolescents with complex congenital heart disease and their amount of physical activity depending on disease severity, utilizing the GPAQ developed by the $\mathrm{WHO}$, and to derive factors influencing the physical activity of adolescents with complex congenital heart disease. It is expected that the findings of this study will be utilized as a basis for developing of nursing interventions and educational programs aimed at promoting physical activity among adolescents with complex congenital heart disease, and that this study will help enable a healthy transition from adolescence to adulthood.

\section{Objectives}

The objective of this study was to examine the characteristics of adolescents with complex congenital heart disease and their amount of physical activity depending on disease severity, and to analyze factors influencing their physical activity.

- Disease severity in adolescents with complex heart disease was examined.

- The impact of differences in various characteristics of adolescents with complex heart disease on their physical activity was examined.

- The impact of differences in disease severity of adolescents with complex heart disease on their physical activity was examined.

- The correlations between physical activity, self-efficacy, and parental attitude in adolescents with complex heart disease were examined.

- Factors influencing the physical activity of adolescents with complex congenital heart disease were derived.

\section{METHODS}

\section{Study Design}

This is a descriptive study conducted to examine factors that influence physical activity in adolescents with complex congenital heart disease.

\section{Study Subjects and Data Collection}

This study involved patients aged 12 to 18 years who had 
been diagnosed with complex congenital heart disease at a tertiary care hospital located in Seoul, and were under ambulatory tracking and monitoring at the pediatric cardiology or pediatric cardiac surgery department.

To determine the number of subjects necessary for multiple regression analysis, the G-power 3.1.9.2 program was used. The significance level was set to .05 . The power of the test was set to .95 and six predictors were analyzed (gender, participation in physical education classes at school, New York Heart Association (NYHA) classification, self-efficacy, paternal care as a sub-item of parental attitude, and sedentary behaviour). When the effect size was set to .30 similar to a previous study [16], the appropriate sample size was calculated to be 77. The final sample size was 93 as a high drop-out rate (15\%) was expected. Ninety-two copies (99\%) of the questionnaire were collected and utilized for the final analysis, out of 93 distributed.

\section{Research Tools}

\section{1) Characteristics of adolescents with complex congenital heart disease}

Nine questions collected general information about the participants, including age, gender, current residential area, school/grade, type of school, school performance, participation in physical education classes at school, financial condition, and body mass index (height and weight). Six questions were on disease characteristics, including a confirmed diagnosis of congenital heart disease, number of operations to date, age at first surgery, number of medications currently taken, and whether advice was given by medical staff regarding physical activity. As a biological index, oxygen saturation at rest was also recorded.

\section{2) Disease severity}

Disease severity was determined by two measures: congenital heart disease (CHD) complexity and the NYHA classification.

The first method (CHD complexity) classified complex congenital heart diseases as being of moderate or great complexity based on the structure of congenital heart disease, as proposed in the ACC/AHA 2018 Guideline published by the American College of Cardiology (ACC) and the AHA [17]. The classification of moderate or great complexity was made based on echocardiography, and great complexity was considered to indicate a higher level of disease severity.

The second method was the NYHA classification, which divides cardiac functional states into stages I to IV. Questions from the translated version were used, as it was designed to include questions for better patient understanding. The high- er the class, the higher the level of disease severity [18].

\section{3) Physical activity}

Physical activity was measured using the GPAQ developed by the WHO. The GPAQ consists of 15 questions - six questions about physical activity at school (work-related activity), six questions about after-school activity of sports (leisure activity), and three questions about travel to and from places as well as one question about sedentary behaviour [15]. For our analysis, the amount of physical activity was classified as moderate to vigorous intensity, and the total amount of physical activity was converted into metabolic equivalents of task (METs) (minutes/week): Vigorous-intensity physical activity was given a rating of $8 \mathrm{METs}$, and moderate-intensity physical activity and relocation was rated as 4 METs. Higher values of the METs corresponded to greater, amounts of physical activity.

\section{4) Self-efficacy}

To measure the level of self-efficacy specifically relevant to physical activity as recognized by the participants, the SelfEfficacy Scale developed by Motl et al. [19] was translated into Korean and used after consent was obtained from the author. Each question was measured on a 5-point Likert scale, with 1 point indicating "not at all", 2 points "not in general", 3 points "normal", 4 points "yes in general", and 5 points "always". Higher scores indicated higher levels of self-efficacy associated with physical activity. The tool was translated into Korean, and its content was validated by one professor at a pediatric cardiac surgery department, one professor at a pediatric cardiology department, two professors at a nursing college, and one professional nurse at a pediatric cardiac surgery department. Among the eight questions of the original tool, the item "I can practice physical activity during my free time even if I have a lot of homework to do". was excluded because its contents validity index was .40; however, the remaining 7 questions were used. At the time of development, the Cronbach's $\alpha$ was .84, and in this study, it was .90 [19].

\section{5) Parental attitude}

To measure parents' attitude towards adolescents with complex congenital heart disease, the Korean version of the Parental Bonding Instrument developed by Parker et al. and translated by Song [20] was used after obtaining consent from the developer and translator. It is a self-reporting tool that measures memories up to respondents' 16th year life. Each parent's caring attitude is measured with 25 questions, including 12 questions about care (positive caring attitude items include interest, sensitivity, love, etc.) and 13 questions about overprotection (negative caring attitude items include regulation, requirement, and punishment). Each question is an- 
swered on a 4-point Likert scale, with 0 points for 'very unlike', 1 point for 'moderately unlike,' 2 points for 'moderately like', and 3 points for 'very like'. Some of these questions in this tool are reverse-scored. High scores for a caring attitude and low scores for overprotection correspond to an appropriate parental attitude. Regarding the Cronbach's $\alpha$ values for this tool in the study of Song [20], the scores were .87 for maternal care, .87 for maternal overprotection, .90 for paternal care, and .87 for paternal overprotection. The Cronbach's $\alpha$ values in this study were .87 for maternal care, .77 for maternal overprotection, .88 for paternal care, and .75 for paternal overprotection.

\section{Method of Data Collection}

The researcher obtained approval for this study from the hospital's Institutional Review Board (IRB) (No. 2018-0444). Hospital permission and cooperation for the survey also were obtained from the nursing department, pediatric cardiac surgery department, pediatric cardiology department, and ambulatory care team. The structured questionnaire was filled out by the participants, and the survey took about 10 minutes to complete. Survey respondents were given a token gift and data collection lasted for 7 months, from April 16 to November 30, 2018.

\section{Data Analysis}

The collected data were analyzed using SPSS version 25.0 (IBM Corp., Armonk, NY, USA). The extent of physical activity depending on participants' characteristics and disease severity was analyzed in terms of frequency, percentage, average, and standard deviation. Differences in physical activity depending on participants' characteristics and disease severity were analyzed using the independent $t$-test and analysis of variance (for post-hoc analysis, the Scheffé test was used). The correlations among the research variables were analyzed by Pearson correlation analysis. Finally, stepwise multiple linear regression was conducted to derive factors on influencing physical activity in adolescents with complex congenital heart disease.

\section{RESULTS}

\section{General and Disease-related Characteristics of Adoles- cents with Complex Congenital Heart Disease}

Ninety-two adolescents with complex congenital heart disease participated in the study, and their general characteristics are presented in Table 1 . The average age of the partic- ipants was $15.03 \pm 1.92$ years, and more participants were male than female $(54,58.7 \%)$. Seventy-nine participants $(85.9 \%)$ attended physical education classes at school. Regarding disease characteristics, participants who had undergone three or more operations accounted for the largest portion of the study population (41, 44.6\%). Oxygen saturation levels ranged between $77 \%$ and $100 \%$, with an average of $94.90 \% \pm 3.75 \%$. The maximum number of cardioactive medications taken was five. Fifty participants (54.4\%) were no longer taking medications. The most common medication taken was warfarin. Among the 92 individuals, the majority $(72,78.3 \%)$ had never received any advice from medical staff (doctors and nurses) regarding the importance of physical activity.

\section{Disease Severity}

Disease severity was categorized as shown in Table 2. Complex congenital heart disease types were classified based on the ACC/AHA 2018 Guideline. Forty-three participants (46.7 $\%)$ were classified as having moderate-complexity disease, while 49 (53.3\%) had disease of great-complexity. Participants were classified based on NYHA class as an indicator of their current cardiac functional status (i.e., the extent of cardiac insufficiency), as follows: 76 (82.6\%) belonged to NYHA class I, $12(13.0 \%)$ to Class II, $4(4.4 \%)$ to class III, and $0(0.0 \%)$ to class IV.

\section{The Amount of Physical Activity among Adolescents with Complex Congenital Heart Disease and Differ- ences in Physical Activity Based on Their Character- istics}

The total amount of physical activity among adolescents with complex congenital heart disease was presented as METs (minutes/week). The average amount of physical activity was $1710.00 \pm 1562.64 \mathrm{METs}$, and the average time spent sitting was $10.94 \pm 2.70$ hours/day. The amount of physical activity was significantly higher among: 1) male students as compared to female students ( $t=4.46, p<.001) ; 2)$ students who attended physical education classes at school compared to those who did not $(\mathrm{t}=6.77, p<.001)$; and 3) participants who underwent their first surgery at the age of 1 or older as compared to those who underwent their first surgery before 1 year of age $(\mathrm{t}=2.08, p=.041)$ (Table 3$)$.

\section{Differences in Physical Activity Depending on Disease Severity}

Differences in physical activity depending on disease severity were noted (Table 3). The amount of total physical ac- 
Table 1. Characteristics of Adolescents with Complex Congenital Heart Disease

\begin{tabular}{|c|c|c|c|c|}
\hline Variables & Characteristics & Categories & $\mathrm{n}(\%)$ & $\mathrm{M} \pm \mathrm{SD}$ \\
\hline \multirow[t]{20}{*}{ General } & \multirow[t]{2}{*}{ Age (year) } & $12 \sim 15$ & $48(52.2)$ & \multirow[t]{14}{*}{$15.03 \pm 1.92$} \\
\hline & & $16 \sim 18$ & $44(47.8)$ & \\
\hline & \multirow[t]{2}{*}{ Gender } & Male & $54(58.7)$ & \\
\hline & & Female & $38(41.3)$ & \\
\hline & \multirow[t]{2}{*}{ Residence area } & Urban & $35(38.0)$ & \\
\hline & & Rural & $57(62.0)$ & \\
\hline & \multirow[t]{3}{*}{ School type } & Middle school & $45(48.9)$ & \\
\hline & & High school & $42(45.7)$ & \\
\hline & & Others* & $5(5.4)$ & \\
\hline & \multirow[t]{3}{*}{ School performance } & Top & $13(14.1)$ & \\
\hline & & Middle & $49(53.3)$ & \\
\hline & & Bottom & $30(32.6)$ & \\
\hline & \multirow{2}{*}{$\begin{array}{l}\text { Participation in } \\
\text { physical education class }\end{array}$} & Yes & $79(85.9)$ & \\
\hline & & No & $13(14.1)$ & \\
\hline & \multirow[t]{3}{*}{ BMI $\left(\mathrm{kg} / \mathrm{m}^{2}\right)$} & Underweight $(<20)$ & $45(48.9)$ & \multirow[t]{6}{*}{$21.07 \pm 3.72$} \\
\hline & & Normal (20 24.9) & $33(35.9)$ & \\
\hline & & Overweight \& obese $(>25)$ & $14(15.2)$ & \\
\hline & \multirow[t]{3}{*}{ Perceived economic condition } & Above average & $11(12.0)$ & \\
\hline & & Average & $69(75.0)$ & \\
\hline & & Below average & $12(13.0)$ & \\
\hline \multirow[t]{13}{*}{ Disease } & \multirow[t]{3}{*}{ Number of surgical procedures } & One & $26(28.2)$ & \multirow{13}{*}{$94.90 \pm 3.75$} \\
\hline & & Two & $25(27.2)$ & \\
\hline & & $\geq$ Three & $41(44.6)$ & \\
\hline & \multirow[t]{2}{*}{ Age at the first surgical procedure } & $<1$ year & $71(77.2)$ & \\
\hline & & $\geq 1$ year & $21(21.8)$ & \\
\hline & $\mathrm{SpO}_{2}$ & & & \\
\hline & \multirow[t]{3}{*}{ Number of medications } & None & $50(54.4)$ & \\
\hline & & One & $22(23.9)$ & \\
\hline & & Two or more & $20(21.7)$ & \\
\hline & \multirow{4}{*}{$\begin{array}{l}\text { Health professional who } \\
\text { gave advice on physical activity }\end{array}$} & None & $72(78.3)$ & \\
\hline & & Doctor & $15(16.3)$ & \\
\hline & & Nurse & $3(3.2)$ & \\
\hline & & Doctor \& nurse & $2(2.2)$ & \\
\hline
\end{tabular}

*Including taking the qualification examination, while studying abroad; $\mathrm{BMI}=$ Body mass index; $\mathrm{SpO}_{2}=$ Saturation of percutaneous oxygen.

tivity was significantly higher among participants with moderate-complexity disease as compared to those with disease of great- complexity $(\mathrm{t}=2.31, p=.023)$, and higher levels of physical activity were also observed among participants belonging to NYHA class I than among those in classes II to III $(\mathrm{t}=5.83, p<.001)$.

\section{Factors Influencing Physical Activity in Adolescents with Complex Congenital Heart Disease}

Stepwise multiple linear regression was conducted based on six variables including self-efficacy $(\mathrm{r}=.52, p<.001)$, paternal care $(\mathrm{r}=.21, p=.046)$, sedentary behaviour $(\mathrm{r}=-.33, p=.001)$ (Table 4), classifications identified as significant factors as such as gender, attendance of school physical education classes, and the NYHA classification. The age at which participants underwent their first surgery showed a significant relationship with CHD complexity $\left(x^{2}=6.08, p=.014\right)$. Additionally, CHD complexity was significantly correlated with the NYHA classification as a variable indicating disease severity in the present study $\left(x^{2}=6.56, p=.013\right)$. Therefore, the stepwise regression analysis was conducted solely based on the NYHA 
Table 2. Classification of Participants by Complexity of Congenital Heart Disease Diagnosis and New York Heart Association Class

$(\mathrm{N}=92)$

\begin{tabular}{clc}
\hline Characteristics & Categories & $\mathrm{n}(\%)$ \\
\hline Moderate & TOF & $24(26.1)$ \\
complexity & Complete AVSD & $4(4.3)$ \\
& Partial AVSD & $2(2.2)$ \\
& CoA & $7(7.3)$ \\
& Congenital mitral valve disease & $2(2.2)$ \\
& Congenital aortic valve disease & $1(1.1)$ \\
& Supravalvular aortic stenosis & $3(3.3)$ \\
Great & Total & $43(46.7)$ \\
& PA & $4(4.3)$ \\
& TGA & $7(7.6)$ \\
& MA & $1(1.1)$ \\
& DORV & $2(2.2)$ \\
& Truncus arteriosus & $3(3.3)$ \\
& FSV & $32(34.8)$ \\
& Total & $49(53.3)$ \\
NYHA class & Class I & $76(82.6)$ \\
& Class II & $12(13.0)$ \\
& Class III & $4(4.4)$ \\
& Class IV & $0(0.0)$ \\
\hline
\end{tabular}

*Including double inlet left ventricle, tricuspid atresia, hypoplastic left heart syndrome, and any other anatomic abnormality with a functionally single ventricle; $\mathrm{TOF}=$ Tetralogy of Fallot; $\mathrm{AVSD}=$ Atrioventricular septal defect; $\mathrm{CoA}=$ Coarctation of the aorta; $\mathrm{PA}=$ Pulmonary atresia; $\mathrm{TGA}=$ Transposition of the great arteries; $\mathrm{MA}=$ Mitral atresia; DORV=Double outlet right ventricle; FSV=Functionally single ventricle; NYHA class= New York Heart Association classification.

classification, which was found to have a more significant relationship with participants' physical activity as a disease severity factors. The factors that significantly influenced physical activity in adolescents with complex congenital heart disease included self-efficacy $(\beta=.41, p<.001)$, gender $(\beta=.37, p<$ $.001)$, and participation in school physical education classes $(\beta=.19, p=.042)$. The tolerance of these independent variables was 0.85 to 0.99 , and the variation inflation factor was between 1.01 and 1.18, indicating multicollinearity. The explanatory power of the model was high, at $42.2 \%(\mathrm{~F}=20.21, p<.001)$ (Table 5).

\section{DISCUSSION}

This study applied the GPAQ developed by the WHO to examine the amount of physical activity of adolescents with complex congenital heart disease. Factors influencing physical activity were derived based on disease severity, self-efficacy, and parental attitude.

First, the average amount of physical activity of adolescents with complex congenital heart disease was $1710.00 \pm 1562.64$ METs (minutes/week), which was less than the WHO physical activity recommendation of at least 60 minutes per day (intense physical activity at a moderate to vigorous level) for children and adolescents aged 5 to 17 years. This is similar to findings in a previous study in which $34.1 \%$ of adolescents with complex congenital heart disease matched the recommended level of physical activity, which was a lower proportion than observed for both normal adolescents $(64.1 \%)$ and for adolescents with simple congenital heart disease (54.5\%) [11].

The following factors influenced physical activity in adolescents with complex congenital heart disease. Self-efficacy had a significant positive correlation with physical activity in adolescents with complex congenital heart disease, and it affected physical activity, similar to the findings of Ray and Henry et al. [12]. Individuals with high self-efficacy maintain positive energy and obtain vitality while exercising, feeling less fatigued during physical activity [21]. Hence, self-efficacy can have a positive influence on physical activity. In addition, self-efficacy is related to the parental caring attitude. In this study, self-efficacy was found to be positively correlated with parental care and negatively correlated with parental overprotection. This is similar to the results of Park and Cheon [22], who found that as stable attachment to parents developed, children developed self-confidence to overcome their fears of potential negative results and to manage their feelings successfully. Hence, it is thought that interventions to enhance self-efficacy might begin with attempts to change parents' caring attitude. As parents provide their children with opportunities to feel a sense of achievement and to experience regular successes, maintaining a reasonable caring attitude helps them to develop self-efficacy, which can affect physical activity directly or indirectly $[23,24]$. However, interventions are necessary since parents of adolescents with congenital heart disease tend to practice overprotection [14]. To improve self-efficacy, therefore, parents of adolescents with congenital heart disease need help to develop not overprotection, but a desirable caring attitude that would help their children experience successes through physical activity with regular verbal encouragement.

Paternal care was positively correlated with physical activity but was not found to be a factor influencing physical activity. In contrast, Määttä, Ray, and Roos [25] noted that parents had a positive influence on their children's physical activity in a variety of ways: Parental encouragement and involvement influenced children's perceptions and cognitions about physical activity positively, and these factors increased the levels of children's physical activity and self-efficacy. In particular, having their fathers as a role model - specifically as children watched their fathers participate in sports or learned that their fathers also enjoyed sports had a direct impact on children's physical activity. Brouwer et al. [26] reported that 
तิ

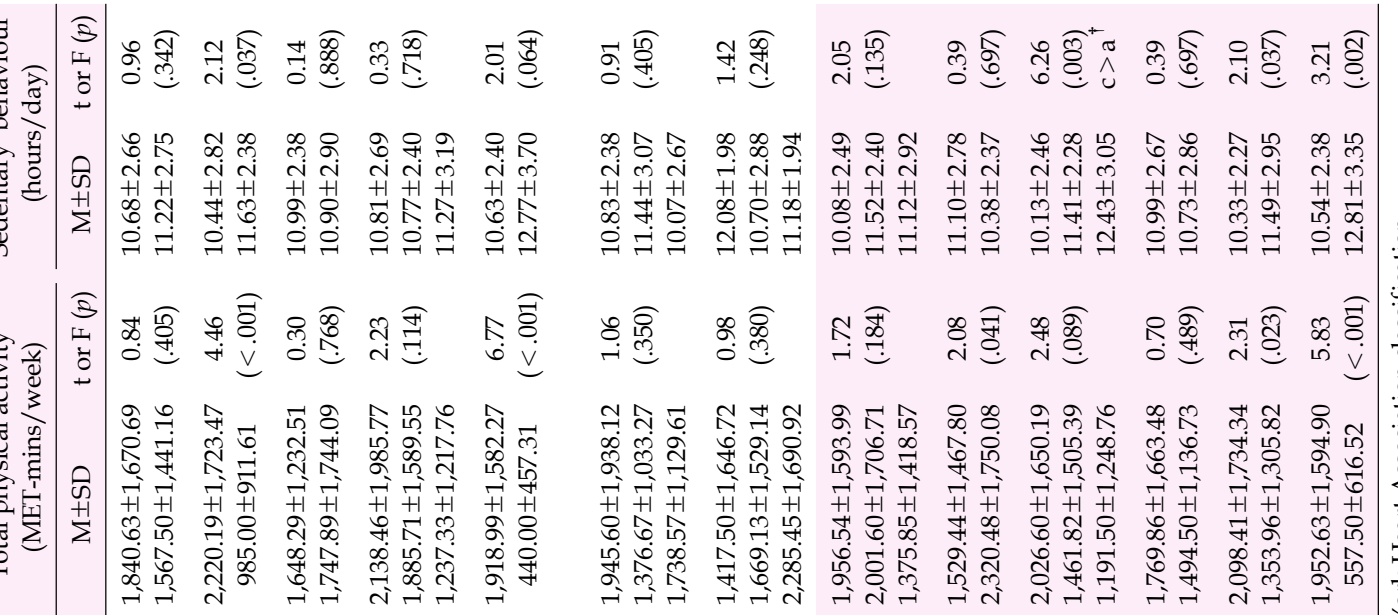

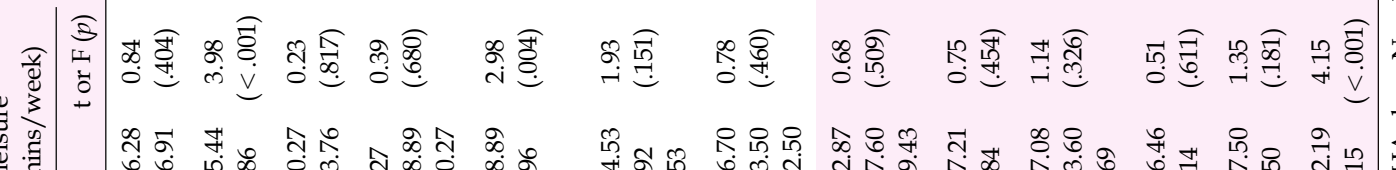

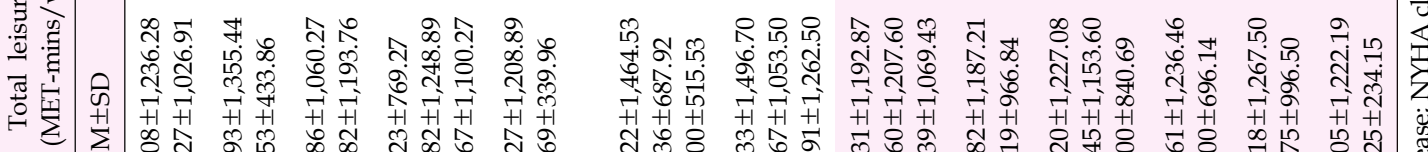

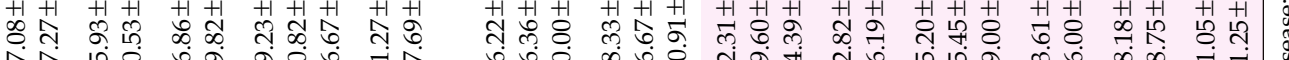

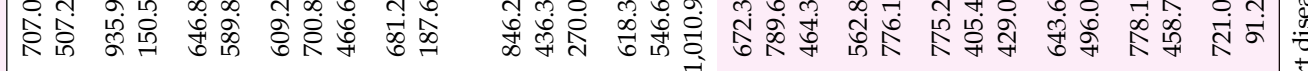

व

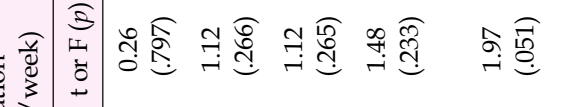

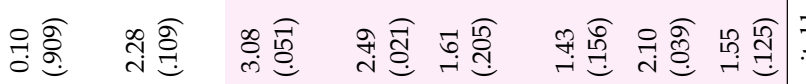

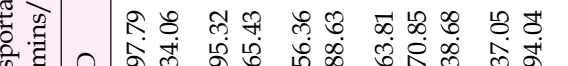

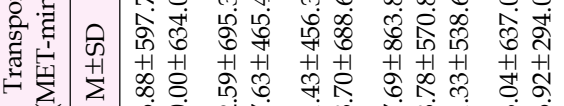

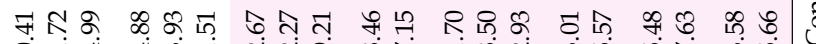

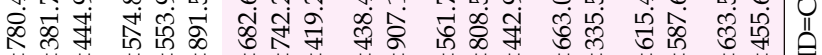

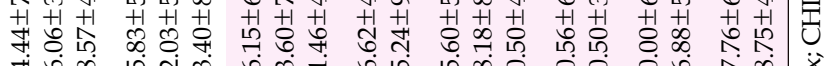

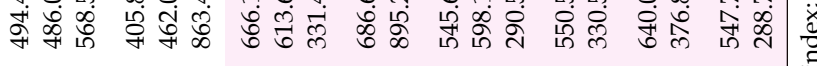


Table 4. Correlations between Physical Activity, Self-efficacy, and Parental Attitude

$(N=92)$

\begin{tabular}{|c|c|c|c|c|c|c|c|}
\hline \multirow{2}{*}{ Variables } & 1 & 2 & 3 & 4 & 5 & 6 & 7 \\
\hline & $r(p)$ & $\mathrm{r}(p)$ & $\mathrm{r}(p)$ & $\mathrm{r}(p)$ & $\mathrm{r}(p)$ & $\mathrm{r}(p)$ & $\mathrm{r}(p)$ \\
\hline 1. Self-efficacy & 1 & & & & & & \\
\hline 2. Maternal care & $.29(.007)$ & 1 & & & & & \\
\hline 3. Maternal overprotection & $-.38(<.001)$ & $-.47(<.001)$ & 1 & & & & \\
\hline 4. Paternal care & $.37(.001)$ & $.72(<.001)$ & $-.41(<.001)$ & 1 & & & \\
\hline 5. Paternal overprotection & $-.29(.007)$ & $-.43(<.001)$ & $.81(<.001)$ & $-.37(<.001)$ & 1 & & \\
\hline 6. Sedentary behaviour & $-.33(.001)$ & $-.02(.823)$ & $.19(.081)$ & $-.01(.958)$ & $.17(.124)$ & 1 & \\
\hline 7. Total physical activity* & $.52(<.001)$ & $.09(.424)$ & $-.18(.095)$ & $.21(.046)$ & $-.10(.361)$ & $-.33(.001)$ & 1 \\
\hline
\end{tabular}

*Total physical activity=Total school+transportation+total leisure.

Table 5. Factors Affecting Physical Activity in Adolescents with Complex Congenital Heart Disease

$(N=92)$

\begin{tabular}{|c|c|c|c|c|c|c|}
\hline Variables & (Reference) & B & SE & $\beta$ & $\mathrm{t}$ & $p$ \\
\hline (Constant) & & $-2,017.02$ & 535.40 & & 3.77 & $<.001$ \\
\hline Self-efficacy & & 99.68 & 22.08 & .41 & 4.51 & $<.001$ \\
\hline Gender & (Female) & $1,167.28$ & 267.72 & .37 & 4.36 & $<.001$ \\
\hline $\begin{array}{l}\text { Participation in } \\
\text { physical education class }\end{array}$ & (No participation) & 850.21 & 411.28 & .19 & 2.07 & .042 \\
\hline
\end{tabular}

children tended to imitate the physical activity of the parent of the same gender, and that the father's type of work, time spent with the father, and knowledge regarding health behaviors affected the son's physical activity. The finding of this study that paternal care was positively correlated with physical activity in adolescents with complex congenital heart disease is thought to be related to the fact that in this study, there were more male participants (58.7\%) than female participants $(41.3 \%)$, and that paternal influence was therefore regarded as significant. Parents of the same gender need to be role models for their children in terms of physical activity. In this regard, follow-up studies should examine the effects of social environments, such as parental disposition and occupation, on children's physical activity. In addition, it is necessary to inform parents that the father's role is as important as the mother's in childcaring because parental caring attitude, and particularly paternal care, has positive effects on physical activity. Meanwhile, excessive protection by parents needs to be avoided.

This study verified gender to be a factor influencing physical activity in adolescents with complex congenital heart disease. The amount of time spent on physical activity was significantly larger among male participants than female participants, which corresponds to the findings of a previous study
[27]. However, the difference in the amount of time spent on physical activity depending on gender is not limited to adolescents with congenital heart disease. In general, male adolescents tend to be more motivated to perform physical activity than females. While male adolescents participate in physical activity mainly for reasons related to personal identity, female adolescents tend to participate in physical activity to maintain their figure and weight or as a way to spend time together with their friends [28]. For this reason, male adolescents spend more time engaging in physical activity than female adolescents, and they may become interested in different sports depending on gender. In other words, since gender differences are an important factor when it comes to physical activity, it is necessary to consider gender, in addition to patients' diagnoses and physical condition, when emphasizing the importance of physical activity to adolescents with complex congenital heart disease in order to motivate them as effectively as possible to engage in physical activity and when giving them guidance on the most suitable types of physical activity.

Finally, it was found that attending in school physical education classes influenced physical activity in adolescents with complex congenital heart disease. Participation in physical education classes at school was related to the NYHA classi- 
fication which indicated the extent of cardiac insufficiency. Specifically, of the participants who did not attend physical education classes at school, $8(62 \%)$ were categorized as NYHA class II or III. This indicates that among adolescents with complex congenital heart disease, a greater severity of disease was related to a lower rate of participation in physical education classes at school.

Statistically significant differences in the amount of time spent engaging in physical activity were also observed according to CHD complexity and the NYHA classification, as indices of disease severity. However, these were not found to be factors that influenced physical activity in the stepwise regression analysis, for the following reasons. First, this study only examined the amount of physical activity only among adolescents with complex congenital heart disease, and did not include adolescents with simple congenital heart disease. Hence, there was a statistically significant difference between the participants with moderate-complexity disease and those with disease of great-complexity, but it was not found to be a factor influencing physical activity. Second, the percentage of participants in NYHA classes II to III was smaller than that of participants in NYHA class I, and most survey respondents were outpatients whose physical symptoms were controlled. For this reason, the NYHA classification was not an influencing factor.

Nonetheless, the NYHA classification is an important clinical tool for the assessment of patients with congenital heart disease. It has significant correlations with brain natriuretic peptide levels and peak oxygen uptake, making it a useful index to assess the prognosis of patients with congenital heart disease. It is recommended that the NYHA classification of patients should be checked each visit to the hospital [29]. The NYHA classification needs to be checked on a regular basis for adolescent outpatients with congenital heart disease in order to facilitate continuous monitoring of high-risk patients who spend a small amount of time engaging in physical activity. In addition, it is necessary to examine individuals' diagnoses and cardiac functional status to determine the scope and possibility of physical activity and to offer appropriate education on the recommended range of physical activity. Furthermore, physical activity needs to be encouraged with due consideration of individuals' attitudes toward physical activity, interests, gender, extent of cardiac insufficiency, NYHA classification, and CHD complexity in relation to the diagnosis.

When adolescents with congenital heart disease have to make decisions about physical activity, advice from medical staff regarding physical activity is of great importance in terms of self-efficacy, in addition to the direct importance of such advice for facilitating physical activity. Therefore, encouragement and advice on physical activity from medical staff are essential for adolescents with complex congenital heart disease [30]. Among the survey respondents in this study, however, 72 individuals $(78.3 \%)$ answered that they never received any advice on physical activity from medical staff. This might indicate that while congenital heart disease management in Korea focuses on physical disease conditions, little attention is paid to patient's quality of life or health behaviors [7].

Despite these limitations, it is still possible to enhance patients' self-efficacy and to increase their amount of physical activity, as nurses are both aware of the specific diagnoses of adolescents with complex congenital heart disease and are familiar with suitable forms of physical activity depending on patients' physical characteristics. The combination enables nurses to offer guidance on physical activity tailored to each patient. In addition, early interventions - both for adolescents and for their parents - will contribute to the proper growth and development of children with congenital heart disease. For this purpose, first of all, it is necessary to provide specific information and guidelines on the possible scope of patients' physical activity to nurses caring for patients with congenital heart disease.

This study is significant in that it provides a basis for follow-up through its classification of patients by severity levels and via the reported measurements of the amount of physical activity specifically in adolescents with complex congenital heart disease, as distinct from measurements in patients with congenital heart disease more broadly. In addition, it will be possible to promote enhanced levels of physical activity based on self-efficacy by developing nursing interventions that encourage physical activity in adolescents with complex congenital heart disease and their parents with due consideration of gender and disease severity.

However, since this study applied convenience sampling to patients aged 12 18 years at one hospital, it is unlikely to be representative of all adolescents with complex congenital heart disease in Korea. Therefore, attention needs to be paid to the generalizability of its findings. Since patients with cardiac insufficiency and arrhythmia were excluded from this study, it was not possible to examine the amount of physical activity of NYHA class IV patients with severe cardiac insufficiency, which is a limitation of the sampling of this study. Finally, cross-sectional research involves certain inherent limitations as it samples participants at a single point in time. Future research needs to examine changes in physical activity over time from infancy to adolescence, rather than focusing solely on adolescence in patients with complex congenital heart disease. Doing so would help obtain longitudinal finding relevant for understanding the growth and development of pediatric patients affected by complex congenital heart disease. 


\section{CONCLUSION}

This descriptive study was conducted to examine the factors influencing physical activity in adolescents with complex congenital heart disease, and identified gender, attendance of physical education classes at school, and self-efficacy as factors affecting their physical activity. Hence, to motivate these adolescents effectively, it is necessary to take gender into consideration, as well as their diagnoses and physical conditions when emphasizing the necessity of physical activity and recommending proper types of physical activity. In addition, nursing interventions focusing on self-efficacy by supporting the family and advice from medical staff regarding physical activity are expected to contribute significantly to promoting physical activity in adolescents with complex congenital heart disease, thereby improving their health.

In addition, it is necessary to inform parents that the father's roles, although it was not found to be a factor influencing physical activity, is as important as the mother's role in childcare because parental caring attitude, particularly paternal care, has positive effects on physical activity. Meanwhile, overprotection by parents needs to be avoided. Nurses can play a helpful role as health managers by providing education to adolescents with complex congenital heart disease on the possible range and types of physical activity based on their diagnoses and physical conditions.

The results of this study recommend as follows. First, only $21.7 \%$ of the respondents in this study were given recommendations on physical activity from medical staff. It is necessary to examine the perceptions of health management experts who personally treat adolescents with congenital heart disease, such as doctors, nurses, and school nurses, regarding physical activity in adolescents with congenital heart disease. Second, it is necessary to conduct replication studies on parental attitudes - not only for adolescents, but also for infants, preschool, and school age children - when developing nursing interventions aiming at improving the self-efficacy of children with congenital heart disease. It is also necessary to examine adolescents' peer relationships and social support.

\section{Conflict of interest}

No existing or potential conflict of interest relevant to this article was reported.

\section{REFERENCES}

1. Oh IS. $10 \%$ of babies born during the year are congenital anomalies. Joongang SUNDAY [Internet]. 2016 Jan 17 [cited 2018 Jan 25]. Available from: https://news.joins.com/article/19423963.

2. The Korea heart Foundation. Yearly heart surgery [Internet]. Seoul: The Korea Heart Foundation; 2018 [cited 2018 Jan 25]. Available from:

http://www.heart.or.kr/korean/board/board_renew.php?sa=list \&bid $=2$.

3. Benjamin EJ, Blaha MJ, Chiuve SE, Cushman M, Das SR, Deo R, et al. Heart disease and stroke statistics-2017 update: A report from the American Heart Association. Circulation. 2017;135(10):e146-e603. https://doi.org/10.1161/CIR.000000000000485

4. Ottaviani G, Buja LM. Update on congenital heart disease and sudden infant/perinatal death: From history to future trends. Journal of Clinical Pathology. 2017;70(7):555-562. https://doi.org/10.1136/jclinpath-2017-204326

5. Markus S, Fabienne S, Corina T, Alexander K, Jean-Pierre P, Kerstin $\mathrm{W}$. Challenges of congenital heart disease in grown-up patients. Swiss Medical Weekly. 2017;147:w14495.

https://doi.org/10.4414/smw.2017.14495

6. Choi YJ, Kim HY. Analyzing changes and determinants of selfrated health during adolescence: A latent growth analysis. Child Health Nursing Research. 2018;24(4):496-505.

https://doi.org/10.4094/chnr.2018.24.4.496

7. Lee S, Kim SS. The life of adolescent patients with complex congenital heart disease. Journal of Korean Academy of Nursing. 2010; 40(3):411-422. https://doi.org/10.4040/jkan.2010.40.3.411

8. Swan L, Hillis WS. Exercise prescription in adults with congenital heart disease: A long way to go. Heart. 2000;83(6):685-687. https://doi.org/10.1136/heart.83.6.685

9. Longmuir PE, Brothers JA, de Ferranti SD, Hayman LL, Van Hare GF, Matherne GP, et al. Promotion of physical activity for children and adults with congenital heart disease: A scientific statement from the American Heart Association. Circulation. 2013;127(21): 2147-2159. https://doi.org/10.1161/CIR.0b013e318293688f

10. Duppen N, Takken T, Hopman MTE, ten Harkel ADJ, Dulfer K, Utens EMWJ, et al. Systematic review of the effects of physical exercise training programmes in children and young adults with congenital heart disease. International Journal of Cardiology. 2013; 168(3):1779-1787. https://doi.org/10.1016/j.ijcard.2013.05.086

11. Kim HJ, Yoon ES, Lee SJ, Choo J, Kim SH, Jae SY. Comparison of physical activity and health-related quality of life in adolescents with and without congenital heart disease: A propensity matched comparison. The Korean Journal of Sports Medicine. 2017;35(1): 40-47. https://doi.org/10.5763/kjsm.2017.35.1.40

12. Ray TD, Henry K. Self-efficacy and physical activity in children with congenital heart disease: Is there a relationship? Journal for Specialists in Pediatric Nursing. 2011;16(2):105-112. https://doi.org/10.1111/j.1744-6155.2011.00282.x

13. Sable C, Foster E, Uzark K, Bjornsen K, Canobbio MM, Connolly HM, et al. Best practices in managing transition to adulthood for adolescents with congenital heart disease: The transition process and 
medical and psychosocial issues: A scientific statement from the American Heart Association. Circulation. 2011;123(13):1454-1485. https://doi.org/10.1161/CIR.0b013e3182107c56

14. Reybrouck T, Mertens L. Physical performance and physical activity in grown-up congenital heart disease. European Journal of Preventive Cardiology. 2005;12(5):498-502. https://doi.org/10.1097/01.hjr.0000176510.84165.eb

15. Armstrong T, Bull F. Development of the World Health Organization global physical activity questionnaire (GPAQ). Journal of Public Health. 2006;14(2):66-70.

https://doi.org/10.1007/s10389-006-0024-x

16. Kang H, Yeon K, Han ST. A review on the use of effect size in nursing research. Journal of Korean Academy of Nursing. 2015;45(5): 641-649. https://doi.org/10.4040/jkan.2015.45.5.641

17. Stout KK, Daniels CJ, Aboulhosn JA, Bozkurt B, Broberg CS, Colman JM, et al. 2018 AHA/ACC guideline for the management of adults with congenital heart disease: Executive summary: A report of the American College of Cardiology/American Heart Association task force on clinical practice guidelines. Journal of the American College of Cardiology. 2019;73(12):1494-1563. https://doi.org/10.1016/j.jacc.2018.08.1028

18. Schoormans D, Mager YL, Oort FJ, Sprangers MAG, Mulder BJM. New York Heart Association class assessment by cardiologists and outpatients with congenital cardiac disease: A head-to-head comparison of three patient-based versions. Cardiology in the Young. 2012;22(1):26-33. https://doi.org/10.1017/S1047951111000825

19. Motl RW, Dishman RK, Trost SG, Saunders RP, Dowda M, Felton $\mathrm{G}$, et al. Factorial validity and invariance of questionnaires measuring social-cognitive determinants of physical activity among adolescent girls. Preventive Medicine. 2000;31(5):584-594. https://doi.org/10.1006/pmed.2000.0735

20. Song JY. The development of the parental bonding instrumentKorean version: Evaluation of the test reliability and validity. Journal of the Korean Neuropsychiatric Association. 1992;31(5):979992.

21. Lee LL, Arthur A, Avis M. Using self-efficacy theory to develop interventions that help older people overcome psychological barriers to physical activity: A discussion paper. International Journal of Nursing Studies. 2008;45(11):1690-1699.

https://doi.org/10.1016/j.ijnurstu.2008.02.012
22. Park WM, Cheon SM. A study on parent attachment, self-concept, self-efficacy and peer relationship of the 6th grade children in elementary school. The Korean Journal od School Psychology. 2008;5 (1):41-59.

23. Kim EJ, Song BO, Cha JY. The relationship of parental child-rearing attitude perceived by high-school students, self-efficacy and social problem solving ability. Korean Journal of Educational Therapist. 2011;3(1):63-76.

24. Gustafson SL, Rhodes RE. Parental correlates of physical activity in children and early adolescents. Sports Medicine. 2006;36(1):79-97. https://doi.org/10.2165/00007256-200636010-00006

25. Määttä S. Ray C, Roos E. Associations of parental influence and 10-11-year-old children's physical activity: Are they mediated by children's perceived competence and attraction to physical activity? Scandinavian Journal of Public Health. 2014;42(1):45-51. https://doi.org/10.1177/1403494813504506

26. Brouwer SI, Küpers LK, Kors L, Sijtsma A, Sauer PJJ, Renders CM, et al. Parental physical activity is associated with objectively measured physical activity in young children in a sex-specific manner: The GECKO Drenthe cohort. BMC Public Health. 2018;18(1):1033. https://doi.org/10.1186/s12889-018-5883-x

27. Fredriksen PM, Ingjer E, Thaulow E. Physical activity in children and adolescents with congenital heart disease. Aspects of measurements with an activity monitor. Cardiology in the Young. 2000; 10(2):98-106. https://doi.org/10.1017/S1047951100006545

28. Kilpatrick M, Hebert E, Bartholomew J. College students' motivation for physical activity: Differentiating men's and women's motives for sport participation and exercise. Journal of American College Health. 2005;54(2):87-94. https://doi.org/10.3200/jach.54.2.87-94

29. Bredy C, Ministeri M, Kempny A, Alonso-Gonzalez R, Swan L, Uebing A, et al. New York Heart Association (NYHA) classification in adults with congenital heart disease: Relation to objective measures of exercise and outcome. European Heart Journal Quality of Care \& Clinical Outcomes. 2018;4(1):51-58.

https://doi.org/10.1093/ehjqcco/qcx031

30. Bar-Mor G, Bar-Tal Y, Krulik T, Zeevi B. Self-efficacy and physical activity in adolescents with trivial, mild, or moderate congenital cardiac malformations. Cardiology in the Young. 2000;10(6):561-566. https://doi.org/10.1017/S1047951100008829 